\title{
Physical Activity, Sedentary Behavior, and Body Mass Index ofStudents during the COVID-19 Pandemic
}

\author{
Fuadi Raja Baja \\ Sport Science Faculty \\ Yogyakarta State University \\ Yogyakarta, Indonesia \\ fuadiraja.2019@student.uny.ac.id
}

\author{
Yustinus Sukarmin \\ Sport Science Faculty \\ Yogyakarta State University \\ Yogyakarta, Indonesia \\ yustinus_sukarmin@uny.ac.id
}

\author{
Faza Annasai \\ Sport Science Faculty \\ Yogyakarta State University \\ Yogyakarta, Indonesia \\ fazaannasai.2020@student.uny.ac.id
}

\begin{abstract}
Physical activity is associated with many factors in the environment of high school students. The coronavirus pandemic and the social restrictions imposed have limited many elements in our environment. Therefore, this study aimed to investigate and describe physical activity and sedentary behavior among senior high school students in confinement. This cross-sectional study involved $\mathbf{5 2}$ students in Yogyakarta. During the pandemic the results of Body Mass Index (BMI) were self-reported by students, and physical activity and sedentary behavior were assessed using the International Physical Activity Questionnaire-Short Form (IPAQSF). Based on the results of data analysis method uses quantitative analysis and is processed into descriptive statistics, namely percentage and mean analysis The results showed that senior high school students were had average moderate physical activity (MPA) equivalent to $(46,15 \%)$ or 1932.12 Metabolic Equivalent of Task (MET) minutes/week during the COVID-19 pandemic. Together with these data, it was concluded that the average physical activity of students was in the moderate category because students were less active in carrying out physical activities, especially during the COVID-19 pandemic where large-scale social restrictions (LSSR/PSBB) was still a mandatory action to be followed along with other preventive measures, so there needs to be an evaluation and improvement in order to increase students' physical activity and fitness especially during the COVID-19 pandemic.
\end{abstract}

Keywords: physical activity, sedentary behavior, body massindex

\section{INTRODUCTION}

The Corona virus disease or known as the COVID-19 is adisease infection caused by the latest type of virus found in 2019 [1]. The kind of virus is transmitted through droplets or sneezing sparks and saliva as well as direct contact with COVID-19 sufferers. Transmission of this virus can be avoided by using several important steps, one of which is by covering the nose with elbows when sneezing and the use of masks and applying physical distancing [2].

Physical distancing as an effort to contain the spread of COVID-19 outbreaks which has an impact on the form of anyrestrictions of human activities in various sectors, one of which is in the field of education. Indonesia's Ministry of Health sees COVID-19 growth as unchanged in the country and decided to limit various types of Citizen activities and implementation of (LSSR) to reduce contagion. Public places such as shopping malls, offices and schools have been closed,forcing various physical activities or activities outside the home to work online. LSSR also affects students' learning to move from face-to-face classes to small groups via online platforms [3]. LSSR also negatively affects students' physicalactivity. This increases the sedentary activity of the student. [4].

In particular with the secondary education level, students no longer come to school to carry out theory and practice face-to- face and replaced with online learning through video conferences. Students who usually actively do physical activity and sports in the school, either through sports subjects or extracurricular activities of the school then lose practice sessionsand sports exercises with online learning from home.

During online learning, most students use video conferencing facilities to connect teachers with students. Thiscauses an increase in the frequency of students using smartphones or other devices for a long time to listen to the learning process and do homework given by their teachers.

The covid-19 pandemic changed human lifestyles, coupled with the release of government regulations on physical distancing made it difficult to do sports activities. It greatly affects human fitness. Striving to break the spread of COVID-19, we should pay more attention to physical activity or exercise regularly [5].

If this is not addressed wisely, then the risks would make students experience lack of movement. In addition, with the restrictions imposed, it tends to make students less active in the house for a long time. It leads to students to experience sedentary lifestyle so that it has a negative impact on them [6]. Lack of movement and lack of exercise can have a negative impact on health because the risk factors for cardiovascular disease and other diseases will increase. [7]. Anumber of studies revealed that lack of movement can reduceimmunity [1]. 
Health is a term which is important in human life since health is needed to carry out daily activities, one way to maintain and improve health is by exercising. During the pandemic COVID-19, everyone is encouraged to maintain health by consuming nutritious, healthy food and doing exercise regularly [8].

\section{METHOD}

\section{A. Study Design}

This cross-sectional study was conducted at the Senior High School students at Yogyakarta, in February to July 2021. The survey contained questions about age, gender, height, and weight. In addition, the IPAQ-SF was used to measure physical activity (PA) in participants. Data collected with the IPAQ-SF were reported as continuous and categorical scores. Sustainability scores are expressed as MET-minutes per week (MET rate $\mathrm{x}$ minutes of activity/day $\mathrm{x}$ days per week). Respondents then self-reported physical activity from the previous seven days. Data collection was carried out on February to July 2021 during the Government Regulation concerning the Enforcement of Large-Scale Social Restrictions for Coping with COVID-19 in Indonesia. All respondents signed an online consent form. Participants in this study are voluntary and confidential.Physical Activity and Sedentary Behaviour

IPAQ-SF was used in this study to measure and determine the sedentary behavior and physical activity of students during the Covid-19 pandemic. Each assigned activity (walking $=3.3$ MET, moderate-intensity activity $=4.0$ MET, vigorousintensity activity $=8.0 \mathrm{MET}$ ) with duration (in minutes) and number of days of activity obtained. Weekly MET minutes are calculated by multiplying the MET factor. concerned is implemented. Total physical activity is the number of weekly MET minutes spent walking and moderate- and vigorousintensity activity. Respondents were then divided into two categories based on their total physical activity: physically inactive ( $<600 \mathrm{MET} \mathrm{min} / \mathrm{week}$ ) and physically active (>600 MET min/week) [12]..

IPAQ-SF is also used to measure and determine students' sedentary habits. All respondents filled out the IPAQ-SF form to find out the time spent on sitting, lying down, reading and watching TV during the pandemic. This duration was further divided into two categories: sedentary time $<8$ hours per day and sitting time $>8$ hours per day [10].

\section{B. Data Analysis}

Data analysis in this study was performed using IBMSPSS version 25.0 (IBM Corp., Armonk, NY, USA).Descriptive statistics are used to describe the appropriate variables. February and July data comparisons were analyzed using the t-test or Wilcoxon test based on the normality of the data distribution. The results of the data are considered significant if the $\mathrm{p}$ value $<0.05$.

\section{RESULTS}

Based on the results of the study, the characteristics of thesubject of this study are shown in Table 1. The average age is 16.9 years. There are more women than men $(53.85 \%$ versus $46.15 \%)$. Findings of this study revealed that $40,39 \%$ students were physically inactive and $59,61 \%$ had physicallyactive. The mean METs for physical activity was 1932.12 during the COVID-19 pandemic. The means was above therecommended sedentary time. Sedentary time that somesubjects spent eight hours or more sedentary during the pandemic. However, some subjects had sufficient physicalactivity $(59.61 \%)$. Students BMI students tend to be in thenormal category, some are thin and overweight. The BMI of the subjects during the pandemic was dominated by the normal category with $25(55,56 \%)$. Students who have the underweight category can be given recommendations in theform of setting food menus that meet calorie needs and bodybuilding such as protein. Meanwhile, for those who areoverweight, it is recommended to set a low-calorie diet/reduce calories and increase physical activity to burncalories for a long time which is included in the aerobic

Table 1. Descriptive statistic of physical activity,sedentary behavior, and BMI

\begin{tabular}{|c|c|}
\hline Variables & $\begin{array}{c}\text { Mean (SD) or } \\
\text { Frequency } \\
(\%)\end{array}$ \\
\hline Gender & 46.15 \\
Male & 53.85 \\
Female & $59.61(31)$ \\
\hline Physical Activity & $40,39(22)$ \\
Physically active & \\
Physically inactive & $48,08(26)$ \\
\hline $\begin{array}{c}\text { Sedentary } \\
\text { Behavior } \\
<8 \mathrm{~h} / \text { day }\end{array}$ & $51,92(27)$ \\
>8h/ day & \\
\hline BMI during & $13.33(6)$ \\
pandemic (kg/m $\left.{ }^{2}\right)$ & $55.56(25)$ \\
Underweight & $37.78(17)$ \\
Normal & 8.89 \\
Overweight & $(4)$ \\
Obese & \\
\hline
\end{tabular}


Table. 2 shows the change in the number of subjects in categorical variables. Test results showed that the number of subjects who spent 8 more hours sitting increased significantly over five months $(\Delta 13.46 \%, \mathrm{p}<0.001)$ withinfive months. The number of students with sufficient physical activity within five months was significantly reduced $(\Delta-17.31 \%, \mathrm{p}<0.001)$.

Table 2. Data Analysis of physical activity, sedentarybehavior, and BMI

\begin{tabular}{|c|c|c|c|c|}
\hline \multicolumn{3}{|c|}{$\begin{array}{c}7 \text { February } \\
2021\end{array}$} & 22 July 2021 & $\mathrm{p}$ \\
\hline $\begin{array}{l}\text { Physical } \\
\text { Activity }\end{array}$ & $\begin{array}{l}\geq 600 \text { Mets } \\
<600 \text { Mets }\end{array}$ & $\begin{array}{l}76,92 \%(40) \\
23,08 \%(12)\end{array}$ & $\begin{array}{l}59.61 \%(31) \\
40,39(\% 22)\end{array}$ & 0,001 \\
\hline $\begin{array}{l}\text { Sedentary } \\
\text { Behavior }\end{array}$ & $\begin{array}{l}<8 \text { Hours/day } \\
<8 \text { Hours/day }\end{array}$ & $\begin{array}{l}38,46 \%(20) \\
61,54 \%(32)\end{array}$ & $\begin{array}{l}51,92 \%(27) \\
48,08 \%(26)\end{array}$ & 0,001 \\
\hline BMI & \begin{tabular}{|} 
Underweight \\
Normal \\
Overweight \\
Obese
\end{tabular} & \begin{tabular}{|c}
$13,46 \%(7)$ \\
$57,69 \%(30)$ \\
$25 \%(13)$ \\
$3,84 \%(2)$
\end{tabular} & $\begin{array}{r}13.33 \%(6) \\
55.56 \%(25) \\
37.78 \%(17) \\
8.89 \%(4)\end{array}$ & 0,001 \\
\hline
\end{tabular}

\section{DISCUSSION}

The study could be one of the few to assess physical activity and sedentary changes during the Covid-19 pandemic. Switching to sedentary lifestyles and Physical activity will have an impact on health in the future. Hypertension, obesity, diabetes, coronaryheart disease, and other diseases related to physical activity and sedentary will increase. Our research shows that sitting time increases significantly after five months during a pandemic due to reduced physical activity. In addition, the number of subjects who had higher sedentary time and inadequate physical activity increased rapidly.

The results of the study believe that LSSR causes a decrease in physical activity and an increase in a sedentary lifestyle, therefore action needs to be taken to prevent these consequences [9] People's lifestyles get worse during quarantine sedentary habits due to spending more time at home, and less time spent on physical activity[10].

Previous studies have also investigated the effects of lockout pandemics on lifestyle and physical activity. A study reported an increase in sedentary behavior and decreased physical activity in children. [11]. The study did not report what was improved by when sedentary \& decreased physical activity during a pandemic. They speculate that less space for physical activity or play could lead to increased sedentary activity and reduced physical activity. One of the factors is the lack of play space which causes a decrease in physical activity, in addition to complying with LSSR policies and refraining from contact with other people., in addition to complying with LSSR policies and refraining from contact with others.

Based on studies in China, there are significant changes such as decreased frequency of active transportation, homework with moderate or high intensity, physical activity at leisure, walking in leisure, improved sedentary lifestyle, sleep patterns, and screen time. This study aims to Another study conducted inChina aims to assess changes in obesity and patterns of physical activity behavior among adolescents and adolescents during pandemics lockdown. [12]. The Italian survey was conducted to assess the effects of pandemics on eating habits and variations in lifestyle during the Covid19 pandemic and it has been found half of the population has gained weight and a slight increase in physical activity. (Di Renzo et al, 2020). However, in the current study most of the 436 students $(69.4 \%)$ spent time sitting in the same place fora longer period of time. And $24.5 \%$ ate snacks between meals throughout the day, $23 \%$ preferred to eat junk food all the time, and $31.4 \%$ wanted to eat fast food and fried foods to eatsometimes. Several other studies have also found a link between BMI and nutritious food intake, including: as nuts, fruits, nuts, vegetables during a lockdown, increased desire toeat fast food, milk, and meat.

It is indeed paradoxical that during the Covid-19 pandemic, people are reducing their physical activity when it has been recommended that they continue to exercise. Exercise has been known to affect the immune system, coagulation and fibrinolytic balance, cellular oxidative stress, and cardiovascular function. [14]. Of course, this positive effect of exercise can boost immunity against viral infections, alleviate symptoms and speed recovery based a Covid-19 infection.

Reducing high physical activity and sedentary during theCovid-19 pandemic will lead to different risks of diseasessuch as diabetes, obesity, coronary heart disease, and death. [15]. In addition, Covid-19 has also been linked to adverse effects on lung damage, coagulation imbalance, heart, and kidney damage. [16]. Inadequate physical activity also increases obesity and increases the risk of hospitalization dueto Covid-19 [17]. It is therefore necessary to avoid reducingphysical activity during the pandemic

With a lack of space available to be physically active, the WHO recommendations for relatively achievable physical activity, especially for students. 
They can use internet- connected devices to follow in exercises through available applications, exercises provided over the Internet, or online training classes. [18]. By using devices, students can search for information related to physical activity and sports to motivate themselves to adopt a healthy lifestyle by doing the recommended physical activities.

WHO guidelines and recommendations for different age groups provide detailed information about the physical activity needed to stay healthy. Children and adolescents aged 5-17 years should, on average, do at least 60 minutes of moderate to vigorous physical activity per week, especially aerobic exercise each week [19]. Good physical activity should include intense aerobic activity, as well as activities that add muscle and bone strength, at least 3 days a week and also limit sedentary time, especially sedentary time and screen time.

The large-scale social restriction (LSSR) does influence sedentary behavior, physical activity, and BMI in students. Physical activity decreases and sedentary habits increase. Students with high sedentary time also experienced an increase, while students with moderate physical activity experienced a significant decrease. The LSSR places studentsat increased risk of disease-related sedentary activity.

\section{CONCLUSION}

Based on the analysis of research data, it is known that there is a significant transformation in the physical activity and sedentary behavior of students during COVID-19. The main thing that stands out is a decrease in physical activity and an increase in students' sedentary habits during the Covid-19 pandemic. Decreased physical activity and increased sedentary behavior are among the factors behind changes in students' BMI.

Based on the conclusions above, it is hoped that the pattern of student sports activities to maintain physical fitnessand health during the Covid-19 is supported by synergistic efforts between related institutions in the fields of education, sports and health. For example, the Ministry of Education and Culture, the Ministry of Youth and Sports, the Ministryof Health in developing learning programs from home while maintaining health and fitness, especially through well- conceived activities and lifestyles.

\section{REFERENCES}

[1] Luzi, L., \& Radaelli, M. G. Influenza and obesity: its odd relationship and the lessons for COVID-19 pandemic. Acta Diabetologica, 57(6), pp. 759-764, 2020.

[2] Jimpson, R. J., \& Katsanis, E. The immunological case for staying active during The COVID-19 pandemic. Brain, Behavior, and Immunity, 87(4), pp.6-7, 2020

[3] Rose, S. Medical student education in the time of COVID19. JAMA, 323(21), pp. 2131, 2020.

[4] Nagata, J. M., Magid, H. S. A., \& Gabriel, K. P. Screen time for children and adolescents during the COVID-19 pandemic. Obesity (Silver Spring), 28(9), pp. 1582-1583, 2020

[5] Nur Kholis, M. Menjaga kebugaran jasmani dan imunitas sebagai pemutus mata rantai COVID-19. Journal of Physical Activity (JPA), 2(1), pp. 8-17, 2021

[6] Kehler, D. S., \& Theou, O. The impact of physical activity and sedentary behaviors on frailty levels. Mechanisms of Ageing and Development, 180(November 2018), pp. 29-41, 2019

[7] Mainous, A. G., Tanner, R. J., Rahmanian, K. P., Jo, A., \& Carek, P. J. effect of sedentary lifestyle on cardiovascula disease risk among healthy adults with body mass indexes 18.5 to $29.9 \mathrm{~kg} / \mathrm{m}^{2}$. AmericanJournal of Cardiology, 123(5), pp. 764-768, 2019.

[8] Nugraha, P. D., Utama, M. B. R., S, A., \& Sulaiman, A. Survey of students sport activity during COVID-19 pandemic. Jurnal Pendidikan Jasmani, Olahraga Dan Kesehatan, 4(1), pp. 11-24. 2020

[9] Margaritis I, Houdart S, El Ouadrhiri Y, Bigard X, Vuillemin A, Duché

P. How to deal with COVID-19 epidemic-related lockdown physical inactivity and sedentary increase in youth? Adaptation of Anses' benchmarks. Arch Public Health. 78(6), 52. 2020

[10] Ammar, A.; Brach, M.; Trabelsi, K.; Chtourou, H. Boukhris, O.; Masmoudi, L.; Bouaziz, B.; Bentlage, E.; How, D.; Ahmed, M.; et al. Effects of COVID-19 home confinement on eating behaviour and physical activity: Results of the ECLB-COVID19 international online survey. Nutrients, 12(6). 1583. 2020

[11] Dunton, G.F., Do, B. \& Wang, S.D. Early effects of the COVID-19 pandemic on physical activity and sedentary behavior in children living in the U.S.. BMC Public Health 20, 1351, 2020.

[12] Yang, S., Guo, B., Ao, L., Yang, C., Zhang, L., Zhou, J., \& Jia, P. Obesity and activity patterns before and during COVID-19 lockdown among youths in China Clinical Obesity. 10, 6m, 2020.

[13] Di Renzo, L., Gualtieri, P., Pivari, F. et al. Eating habits and lifestyle changes during COVID-19 lockdown: an Italian survey. J Transl Med 18, 229, 2020

[14] Dorneles, G. P., Dos Passos, A. A. Z., Romao, P. R. T. and Peres, A. New insights about regulatory $T$ cells distribution and function with exercise: the role of immunometabolism. Curr Pharm Des. 26, pp, 979-990, 2020 .

[15] Huang, Y., Li, L., Gan, Y., Wang, C., Jiang, H., Cao, S., $\& \mathrm{Lu}, \mathrm{Z}$. Sedentary behaviors and risk of depression: A meta-analysis of prospective studies. Translational Psychiatry, 10(1), pp. 1-10, 2020

[16] Liu, J., Zheng, X., Tong, Q., Li, W., Wang, B., Sutter, $K$., et al. Overlapping and discrete aspects of the pathology and pathogenesis of the emerging human pathogenic coronaviruses SARS-CoV, MERS- CoV, and 2019-nCoV. J. Med. Virol. 92, pp. 491-494, 2020.

[17] Dietz, W., \& Santos-Burgoa, C. Obesity and its Implications for COVID-19 Mortality. Obesity (Silver Spring, Md.), 28(6), 1005. 2020.

[18] Tate, D. F., Lyons, E. J., \& Valle, C. G. High-Tech Tools for Exercise Motivation: Use and Role of Technologies Such as the Internet, MobileApplications, Social Media, and Video Games. Diabetes Spectrum : A Publication of the American Diabetes Association, 
28(1), 45-54. 2015

[19] World Health Organization. Global

Recommendations on Physical Activity for Health.

Available online: https://www.who.int/

ncds/prevention/physical-activity/global-action-

plan-2018-2030/en/ (accessed on 30 July 2021). 